\title{
ATMOSPHERE ACTIVITY MEASUREMENT BY LED RAMAN MINI LIDAR \\ Tatsuo Shiina
}

\author{
Graduate School of Engineering, Chiba University, Chiba-shi, Chiba 263-8522, Japan \\ *Email: shiina@faculty.chiba-u.jp
}

\begin{abstract}
The LED mini lidar was improved to monitor Raman scattering echoes. The Raman scattering signal indicates a certain gas concentration and it can distinguish the target from the other materials. It is so weak, 1/1000 of Mie scattering echoes, but even enough to be stimulated from the target gas with LED pulsed beam. At first, we developed a compact Raman lidar with micro pulse DPSS laser to detect hydrogen gas quantitatively. We replaced it with the LED pulse module, which was calculated enough potential to stimulate Raman scattering and detect the target gas. The next task is the activity measurement of such a target gas. To validate the potential of the LED Raman lidar, we conducted the sea surface atmosphere measurement. As a result, the unique relationship between the surface atmosphere and sea water echoes was observed. In this report, we state the concrete specification of the LED mini Raman lidar and some results of the activity observations.
\end{abstract}

\section{INTRODUCTION}

The Raman scattering light has an information of the target gas, which is characteristic Raman shift with the target itself, and we can distinguish the target from the other gases [1]-[2]. It is effective measurement for a certain gas which has no absorption wavelength in visible and near infrared light region [3]-[4]. We have focused on the hydrogen gas detection with a compact Raman lidar with a DPSS laser [5]-[7].

The leakage detection of hydrogen gas is important for the hydrogen gas station and fuel cell manufacture scene. To detect it on site, the lidar should be compact and bring it everywhere. The system has to act with a buttery and its transmitting beam intensity is lowered enough for safety to human eyes. Sometimes, the laser beam is not accepted in certain facilities, for example, in a nuclear power facility. Under such backgrounds, we developed a LED mini Raman lidar, which was replaced the light source of the DPSS laser to a LED pulse module. We calculated the adequate optical power to detect the low percentage hydrogen gas and fixed the concrete lidar design. It could have successfully accomplished the quantitative measurement of the hydrogen gas concentration within $1-100 \%$ [8]-[9].

The next task is the activity monitoring of such a target gas. To examine the precise concentration, the measurement has to follow the target gas flow. That is, the lidar should evaluated its echo within a higher sampling rate. To validate the potential of the LED Raman lidar, we conducted model experiments with a moving target; the sea surface atmosphere measurement. In this report, we state the concrete specification of the LED mini Raman lidar and some results of the atmospheric activity observations.

\section{LED MINI RAMAN LIDAR}

At first, we had calculated the minimum detectable values of Raman scattering intensity referring to the DPSS laser based compact Raman lidar. The verification test was conducted by detecting the actually lowered Raman echo of hydrogen gas. The laser beam is entered into the quartz cell filled with hydrogen gas. The concentration was $100 \%$. As the laser power was gradually decreased up to the detection limit, which is estimated by the numerical analysis. The estimated detection limit was obtained by the transmitting pulse power of $1 \mathrm{~W}$ with the pulse width of $10 \mathrm{~ns}$. The experimental result coincided with the calculation.

Considering the above results, we fixed the design of the LED based mini Raman lidar. The lidar optics was biaxial type and its optical paths to distinguish the gases were as same as the laser based

Table 1 Raman scattering from each molecule.

\begin{tabular}{|l|c|c|c|}
\hline Target & $\begin{array}{l}\text { Raman } \\
\text { Shift }\left(\mathrm{cm}^{-1}\right)\end{array}$ & $\begin{array}{l}\text { Wavelength } \\
(\mathrm{nm})\end{array}$ & $\begin{array}{l}\text { Scattering Cross } \\
\text { section ratio }\end{array}$ \\
\hline $\mathrm{N}_{2}$ & 2331 & 400 & 1 \\
\hline Water & 3440 & 420 & - \\
\hline $\begin{array}{l}\text { Water } \\
\text { Vapor }\end{array}$ & 3652 & 415 & 2.18 \\
\hline $\mathrm{H}_{2}$ & 4160 & 430 & 3 \\
\hline
\end{tabular}


compact Raman lidar. The detecting targets here was the atmospheric nitrogen, water, water vapor and hydrogen gas. Their Raman shifts and its wavelengths against the incident LED beam of $365 \mathrm{~nm}$ were summarized in Table 1 [10]. The LED lamp module had the center wavelength of $365 \mathrm{~nm}$ and its spectrum width was $10 \mathrm{~nm}$. And the wavelengths of Raman scattering echoes become $400 \mathrm{~nm}$ for atmospheric nitrogen, $415 \mathrm{~nm}$ for water vapor, $420 \mathrm{~nm}$ for water, and 430nm for hydrogen gas. Water Raman channel was used to calibrate the water vapor signal in labexperiment. LED beam is not easy to collimate in comparison with the laser beam, while it never focuses after the transmission. It becomes benefit in the closed space for the safety [11]. The diameter of the transmitting beam was $50 \mathrm{~mm} \phi$ and its divergence

Table 2 LED mini Raman lidar specifications.

\begin{tabular}{|l|l|}
\hline Transmitter & $\begin{array}{l}750 \mathrm{~mW}(7.5 \mathrm{~nJ} / 10 \mathrm{~ns}) \\
\text { (NCSU033C Nichia Corp.) }\end{array}$ \\
\hline LED Pulse power & $365 \mathrm{~nm}$ \\
\hline Wavelength & $50 \mathrm{~mm} \phi$ \\
\hline Beam Diameter & $10 \mathrm{mrad}$. \\
\hline Beam Divergence & $>500 \mathrm{kHz}$ \\
\hline Repetition Frequency & Cassegrain type \\
\hline Receiver & $127 \mathrm{~mm} \phi$ \\
\hline Telescope & $<5 \mathrm{mrad}$. \\
\hline Diameter & $\Delta \lambda=10 \mathrm{~nm}$ \\
\hline Field of View & $\begin{array}{l}\text { PMTs (R6350P, Hamamatsu } \\
\text { Photonics K.K.) }\end{array}$ \\
\hline Interference Filters &
\end{tabular}
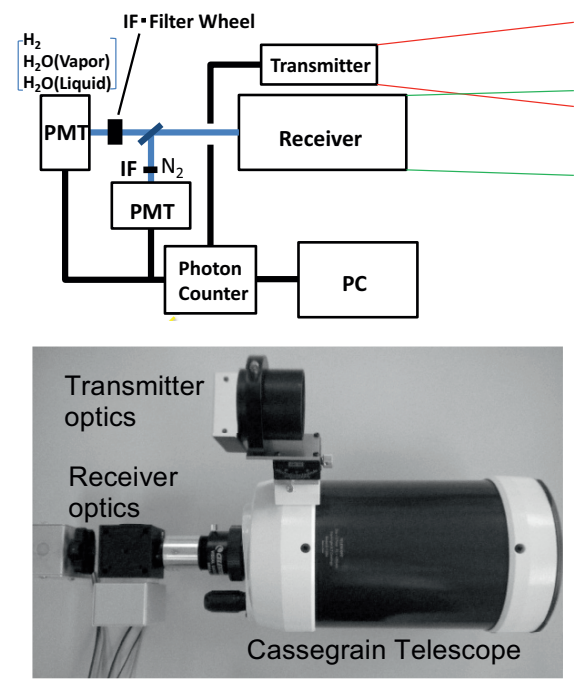

Fig. 1 Optical setup of LED mini Raman lidar. was about $10 \mathrm{mrad}$. The LED pulsed power was $<1 \mathrm{~W}$ (=10nJ/10ns). The pulse repetition frequency was improved to $>500 \mathrm{kHz}$. The receiving telescope was Cassegrain type and its aperture is $127 \mathrm{~mm} \phi$. The receiver's FOV was restricted to $3 \mathrm{mrad}$. The system was so compact and handy that one can use it in any observation scenes. The system power consumption was about $2 \mathrm{~W}$ and could be act with a small PC battery in 10 hours. The specification of the LED mini Raman lidar optics was summarized in Table 2 and its optics was illustrated in Fig.1.

\section{FUNDAMENTAL OBSERVATION}

To catch the target gas flow activity, the lidar should evaluated its echo within a higher sampling rate. The high-speed and high-resolution photon counter was developed for this purpose. It can follow the pulse repetition frequency of $>500 \mathrm{kHz}$. Its time resolution is $>5 \mathrm{~ns}$. It is equivalent to the spatial (distance) resolution of $>0.75 \mathrm{~m}$. It has 4 channels, and their simultaneous measurements are possible with a single input or output trigger signal [12].

Figure 2 shows the results of the atmospheric nitrogen gas and the water vapor measurement. It was conducted in nearly horizontal direction in night time. Accumulation was 3.5 minutes. Nitrogen echo was obtained up to $70 \mathrm{~m}$ (Fig.2(a)). After that the fluorescence echo of the tree was also detected at $80 \mathrm{~m}$.
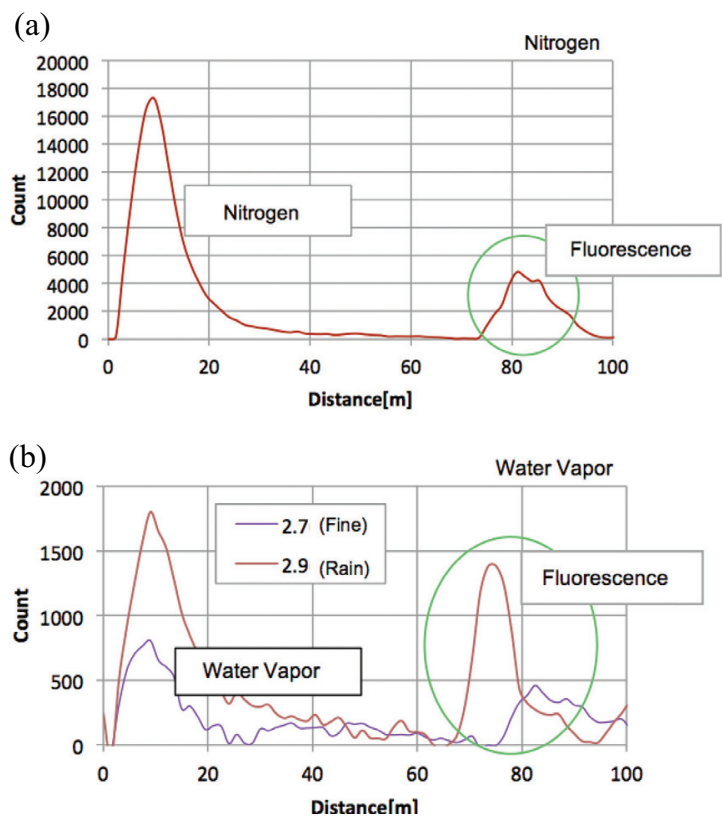

Fig.2 Atmosphere monitoring with nitrogen and water vapor echoes. (a)Nitrogen Raman echo (b)Water vapor Raman echo. 
As the tree leaves scattered the LED beam partially, their echoes were observed over about $20 \mathrm{~m}$. The atmospheric nitrogen was stable and its echo waveform became smooth. On the other hand, the water vapor echo fluctuated because of low counts (Fig.2(b)). It was drastically changed by depending on the humidity. In the figure, the humidity was $25 \%$ on Feb. 7 in fine day, while it was $90 \%$ on Feb. 9 in rain day. The observation range of the water vapor was $70 \mathrm{~m}$, which is equal to that of the nitrogen echo. The fluorescence echoes of trees were detected, too. With the enough summation time, the signal-to-noise ratio improves, while the spatial and temporal activity of the target gas flow are compromised.

\section{SEA SURFACE OBSERVATION}

We conducted the sea surface measurement to verify its activity visualization. Figure 3 shows the concept. The lidar fixes on the top of sea wall or the bow of fisher boat. And the lidar is trained on the surface atmosphere with a shallow angle. The beam divergence is wider than the laser beam, and echo can detect from a few meters to $300 \mathrm{~m}$. Thanks to the shallow angle measurement, the interaction between the surface atmosphere and sea water can be captured. With a certain shorter summation time, their activity is visualized, too. The mini Raman lidar was brought to the coast and set with shallow angle. The location was Inage coast, Chiba, Japan on $8^{\text {th }}$ Dec. 2018. At that time, the weather condition was calm and wind speed was $1.5 \mathrm{~m} / \mathrm{s}$.

The Figure 4 shows the observation results of the atmospheric nitrogen and water vapor echoes. Every echo was stored at $0.5 \mathrm{~s}$ interval. The horizontal axis represents the time and the vertical axis was distance. The echo counts represented with color. One can see that the echoes appeared on $15-25 \mathrm{~m}$ on nitrogen echo and $20-30 \mathrm{~m}$ on water vapor echo, respectively. That is, the nitrogen echo is nearer than the water vapor echo. The hair line like echoes indicates the individual sea waves. From the analysis of them, it is confirmed that the wavelength and speed of sea wave were $8 \mathrm{~m}$ and $2.2 \mathrm{~m} / \mathrm{s}$, respectively, and its period was $3.67 \mathrm{~s}$. The height of the wave was calculated as $2.7 \mathrm{~m}$ by considering the shallow angle orientation. As the statistical consideration, the captured waves on the atmospheric nitrogen echo and the water vapor echo were related each other. Figure 5 indicates the one echoes' A-scope graphes on the images in Fig. 4. It is of interest that

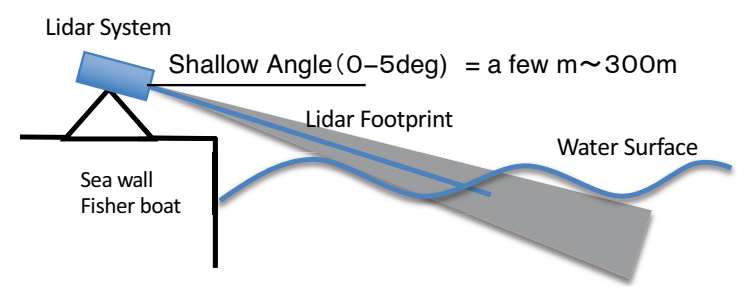

Fig.3 Shallow angle observation with LED Raman lidar.
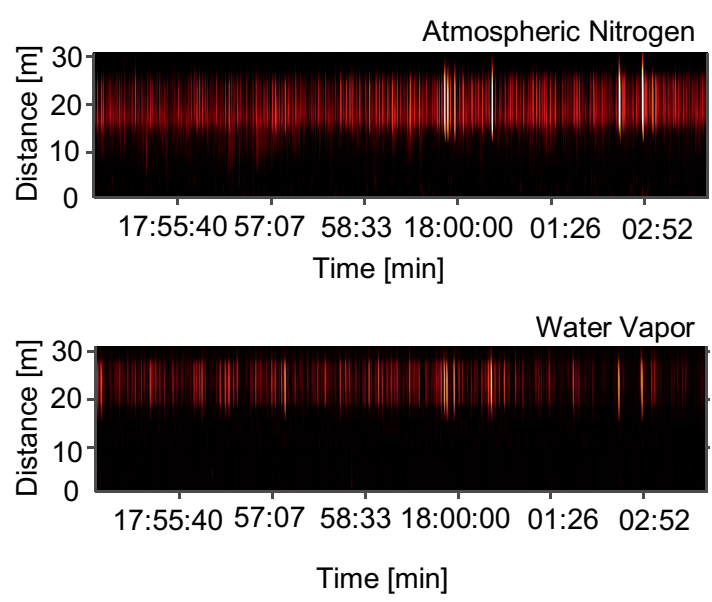

Fig.4 Sea surface atmosphere and water echoes at Inage coast, Chiba, Japan on $28^{\text {th }}$ Dec. 2018.

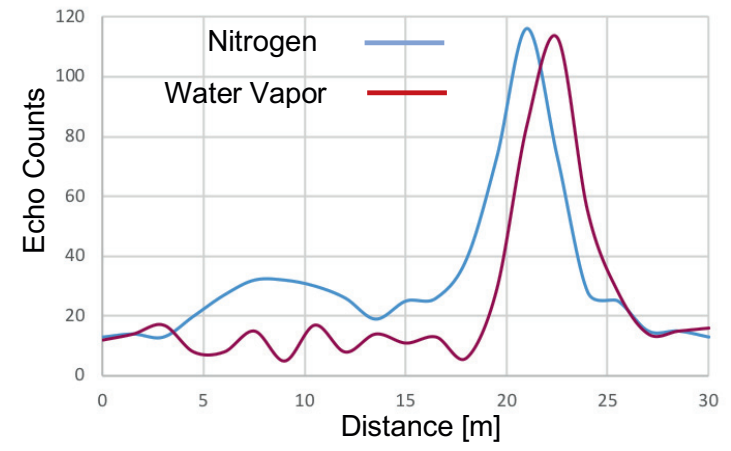

Fig. 5 Interaction between sea surface atmosphere and water echoes at 17:59:57 on 28 $8^{\text {th }}$ Dec. 2018. 
Both of waveforms on Nitrogen echo and Water vapor echo had the same width. It indicates their synchronized motions, too. The stronger intensity echoes were synchronized each other as shown in Fig.4, while the weak intensity echoes of the atmospheric nitrogen had a certain delay against the motion of the water vapor echoes. Figure 6 shows such peak motions on the atmospheric nitrogen and the water vapor echoes in Fig.4. It seems that the nitrogen echoes fluctuate on their delay. It suggests that the sea wave moves with the atmosphere shuffle. The sea wave motion reflects the wind condition, water flow and tide. The bottom feature of the sea also affects the sea wave especially at a shallow. It is confirmed that they were represented on the Raman lidar echoes due to the sea and weather conditions.

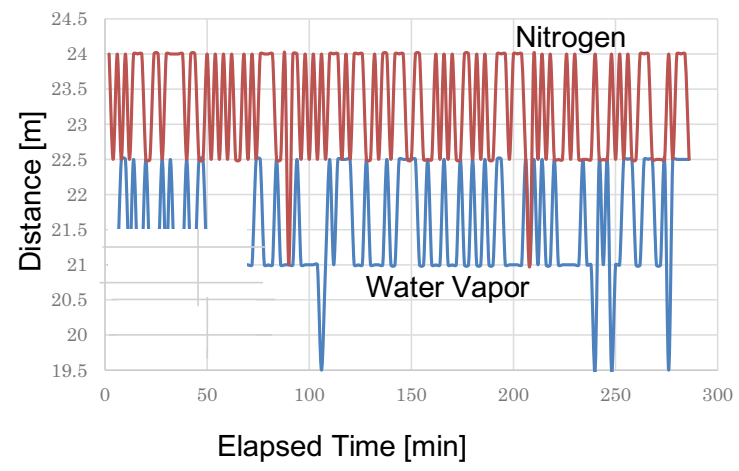

Fig. 6 Peak motions on the atmospheric nitrogen and the water vapor echoes in Fig.4.

\section{SUMMARY}

The LED based mini Raman lidar was proposed and improved. In this study, we focused on the target gas activity. To visualized it, the observation was conducted with the shorter summation time and higher resolution. The atmospheric nitrogen and water vapor were aimed as the targets. The unique behavior of the relationship between the atmospheric nitrogen and water vapor on the sea surface could be successfully visualized.

We have already spread the target to a certain gas as hydrogen and methane gas. Furthermore, the artificial twister was utilized to monitor its activity, too. These results analyzed in view point of quantitative measurement for concentration calculation and activity visualization.
It will lead to the true concentration measurement on the temporal and spatial change.

\section{ACKNOWLEDGEMENTS}

This work was supported by JSPS KAKENHI Grant Number JP16H03129.

\section{REFERENCES}

[1] D. A. Leonard, Nature 216, 142-143, 1967.

[2] S. H. Melfi, , Appl. Opt. 11, 1605-1610, 1972.

[3] H. Gu, Z. Wang and Y. Hu, Sensors, 12, 5517 (2012).

[4] X. Q. Zeng, M. L. Latimer, Z. L. Xiao, S. Panuganti, U. Welp, W. K. Kwok, and T. Xu, Nano letters, 11, 262 (2011).

[5] H. Ninomiya, S. Yaeshima, K. Ichikawa, and T. Fukuchi, Opt. Eng. 46, 094301 (2007).

[6] H. Miya, T. Shiina, T. Kato, K. Noguchi, T. Fukuchi, I. Asahi, S. Sugimoto, H. Ninomiya, Y. Shimamoto, CLEO/Pacific Rim, (2009).

[7] T. Fukuchi and T. Shiina Eds., Industrial Applications of Laser Remote Sensing, Bentham Science Publishers Ltd (2012).

[8] T. Shiina, K. Noguchi, and K. Tsuji, Proceedings of 23th international conference on nuclear engineering (ICONE23), 17 (2015).

[9] Djezzar, B. (Ed.) Ionizing Radiation Effects and Applications; IntechOepn: Chapter 3, London, UK (2018).

[10] R. M. Measures, Laser Remote Sensing; Fundamentals and Applications, John Wiley \& Sons, New York (1984).

[11] T. Shiina, Sensors, 19, 569(2019)

[12] Britun, N.; Nikiforov, A. (Eds). Photon Counting - Fundamentals and Applications, IntechOpen: Chapter 11, London, UK (2018). 